\title{
Classic and Nonclassic \\ Renin-Angiotensin Systems in the Critically III
}

Laurent Bitker, MD, MSc ${ }^{\mathrm{a}, *}$,

Louise M. Burrell, MBChB, MRCP, MD, FRACP

\section{KEYWORDS}

- Acute kidney injury $\bullet$ Acute respiratory distress syndrome $\bullet$ Angiotensin

- Angiotensin-converting enzyme • Sepsis • Inflammation • Septic shock • Renin

\section{KEY POINTS}

- Activation of the endocrine renin-angiotensin system (RAS) cascade induces immediate metabolic, hemodynamic, and renal responses, in response to changes in blood pressure and homeostasis.

- Renin and angiotensin II are upregulated in the setting of sepsis and septic shock. Higher renin and angiotensin II and lower circulating angiotensin-converting enzyme levels are associated with worse survival.

- Classic and nonclassic RASs modulate the inflammatory and immune responses. The angiotensin II axis stimulates a proinflammatory beneficial antibacterial response.

- In patients with vasoplegic shock, the infusion of exogenous angiotensin II lowers vasopressor requirements, and improves renal-related outcomes.

- Experimental evidence supports the direct role of classic RAS in the pathophysiology of acute respiratory distress syndrome, whereas clinical data suggest a lung protective effect of angiotensin-converting enzyme 2 administration.

\section{INTRODUCTION}

The renin-angiotensin systems (RASs) regulate blood pressure, kidney function, and salt and water homeostasis. Modulation of RAS is central in the intensive care unit spectrum of diseases (eg, hemodynamic failure) and is associated with patient outcomes. $^{1-7}$ The RASs are enzymatic cascades implicating sequential peptide

Disclosure Statement: The authors declare that they have no conflicts of interest.

${ }^{a}$ Department of Intensive Care, ICU Research Office, Austin Hospital, 145 Studley Road, Heidelberg, Victoria 3084, Australia; ${ }^{\text {b }}$ Department of Medicine, University of Melbourne, Austin Health, Austin Hospital, 145 Studley Road, Heidelberg, Victoria 3084, Australia

* Corresponding author.

E-mail address: laurent.bitker@austin.org.au 
cleavage, leading to angiotensin generation by angiotensin-converting enzymes (ACEs). ${ }^{8}$ RAS also modulates inflammation and immune responses. ${ }^{8,9}$

The angiotensin (Ang) (1-7)/ACE2 cascade is known as the nonclassic RAS, which acts as an endogenous counterregulatory arm to the angiotensin II (Ang II)/ACE axis. ${ }^{10}$ Both classic and nonclassic RAS have been identified at the tissue level, with paracrine effects dissociated from those of the circulating system. ${ }^{11}$

Better understanding of RAS physiology has led to the development of highpotential therapies, of interest to the intensivist. Administration of exogenous Ang II in vasoplegic shock alleviated vasopressor requirements, and was associated with improved survival in patients with severe acute kidney injury $(\mathrm{AKI}){ }^{2,7}$ On the other hand, exogenous infusion of recombinant human ACE2 has demonstrated exciting lung protective properties in the context of the acute respiratory distress syndrome (ARDS). ${ }^{3}$

The scope of this review was to describe the classic and nonclassic RASs, and their physiologic effects, with an emphasis on their respective pathogenic and/or therapeutic roles in the context of critical illness.

\section{THE CIRCULATING CLASSIC RENIN-ANGIOTENSIN SYSTEM}

Two enzymatic cascades lead to the generation of the main endocrine agents of the classic and nonclassic RASs (see Fig. 2). Both arms exist as an endocrine (circulating) and a paracrine (tissue-based) system, with paracrine and autocrine effects independent of the systemic systems. ${ }^{11,12}$ The organ localizations of the RASs are presented in Fig. 1.

\section{Peptides}

Angiotensinogen is a glycosylated protein, produced by the hepatic lobules. ${ }^{13}$ Plasma levels are stable, and in excess when compared with circulating renin concentrations. Local generation of angiotensinogen also exists in the renal epithelium, brain, heart, adrenal, endothelial, and intestinal tissue. ${ }^{11,12}$ Ang I is a biologically inactive decapeptide generated by the proteolysis of angiotensinogen by renin. ${ }^{9}$

Ang II is the pivotal peptide of the classic RAS. This octapeptide is the product of the cleavage of Ang I by ACE, but may also be generated under the action of other enzymes. ${ }^{9}$ Plasma Ang II is rapidly degraded into Ang III, IV, or Ang (1-7), under the action of various enzymes (Fig. 2).

Ang III is the product of the cleavage of Ang II by aminopeptidase A, or by the cleavage of Ang (1-9) under the action of ACE. ${ }^{9}$ Like Ang II, Ang III is a potent vasopressor, a thirst and salt appetite stimulant, and an activator of aldosterone secretion. ${ }^{14}$ Ang IV mainly modulates cerebral blood flow and cognition, increases renal blood flow (RBF), and decreases water and sodium reabsorption in the renal epithelium. ${ }^{15,16}$

\section{Enzymes}

Renin is an aspartyl-protease released by the juxta-glomerular apparatus, and is the key rate-limiting factor of Ang 11 generation. ${ }^{8}$ Its secretion is regulated by renal perfusion, sodium-chloride balance, sympathetic nervous tone, and Ang II (Box 1). ${ }^{17-19}$ Renin has also been identified in the proximal tubule and distal nephron, the brain, and in some immune system circulating elements. ${ }^{20,21}$

ACE is a dicarboxypeptidase metalloenzyme that generates Ang II, via a zincdependent shedding of a C-terminal dipeptide from Ang I. ACE also generates Ang (1-7) from Ang (1-9), and inactivates bradykinin, a natriuretic and vasodilator 
Central nervous system

- Subfornical organ

- Glia

Peripheral nervous system

- Glia

Lungs:

- Pulmonary endothelium
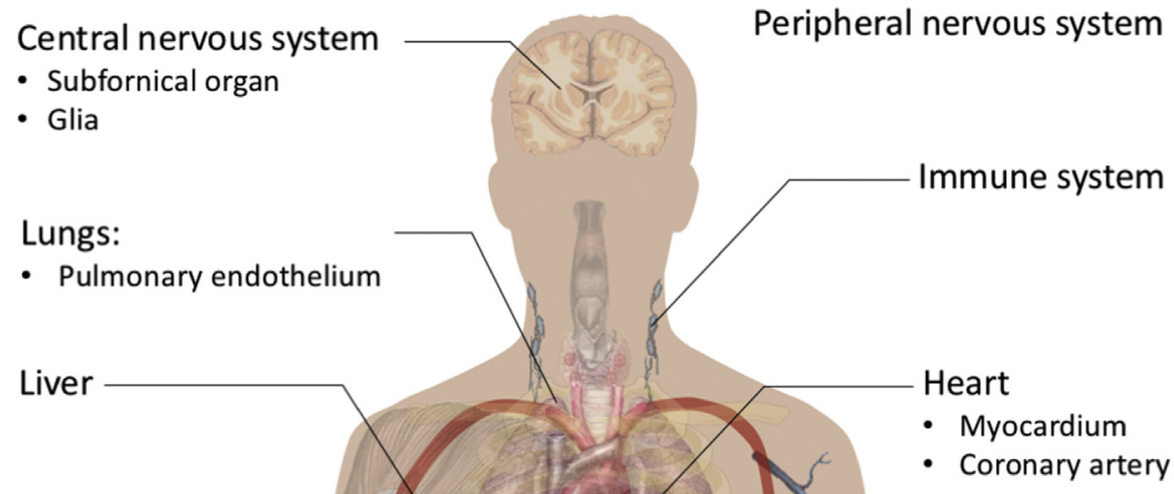

Kidneys

- Glomerulus

- Proximal tubule

- Distal tubule

- Loop of Henle

- Distal collecting ducts

Immune system

- Myocardium

- Coronary artery

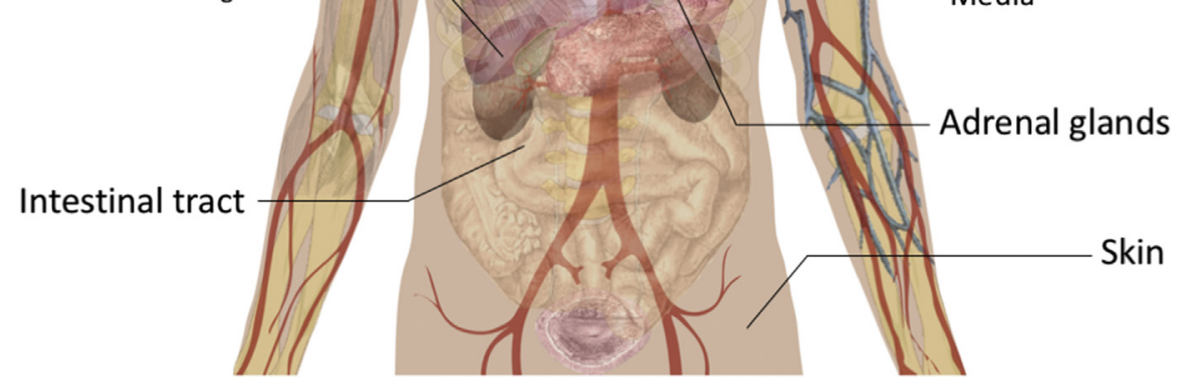

Fig. 1. Localization of RASs. Presented here are the organs or tissues in which at least 1 component of classic and/or nonclassic systems have been identified and are considered as being locally generated and/or secreted.

peptide. ${ }^{22}$ The protein is a transmembrane ecto-enzyme found mainly in the pulmonary endothelium, where most of the Ang II is generated, but also in the brain, heart, and renal endothelium, and immune system cellular components. ${ }^{23-25}$

\section{Receptors}

Ang II receptors are G protein-coupled transmembrane proteins with 7 membranespanning domains. ${ }^{26}$

Angiotensin type 1 receptor $\left(\mathrm{AT}_{1} \mathrm{R}\right)$ represents the principal transductor of Ang II into its main physiologic responses. ${ }^{26} A T_{1} R$ is found in the endothelium (smooth muscular cells), kidneys (glomeruli and proximal tubule), adrenal glands, heart, lymphocytes, and granocytes. ${ }^{27-29}$ Ang II-AT 1 R binding induces the activation of multiple intracellular secondary messenger cascade, including intracellular $\mathrm{Ca}^{2+}$, nuclear factor (NF) $\kappa \mathrm{B}$, phospholipase $\mathrm{C}$ and Janus kinase families. ${ }^{27}$

Angiotensin type 2 receptor $\left(\mathrm{AT}_{2} \mathrm{R}\right)$ presents a $34 \%$ homology with $\mathrm{AT}_{1} \mathrm{R}$ and is similarly structured. ${ }^{26}$ It is found in the endothelium, heart, brain, kidneys and adrenal glands. $\mathrm{AT}_{2} \mathrm{R}$ main actions antagonize those of AT1R. Angiotensin type 4 receptor $\left(A T_{4} R\right)$ is principally located in the brain, and to a lesser extent in the renal artery, and binds Ang IV. ${ }^{15}$ 


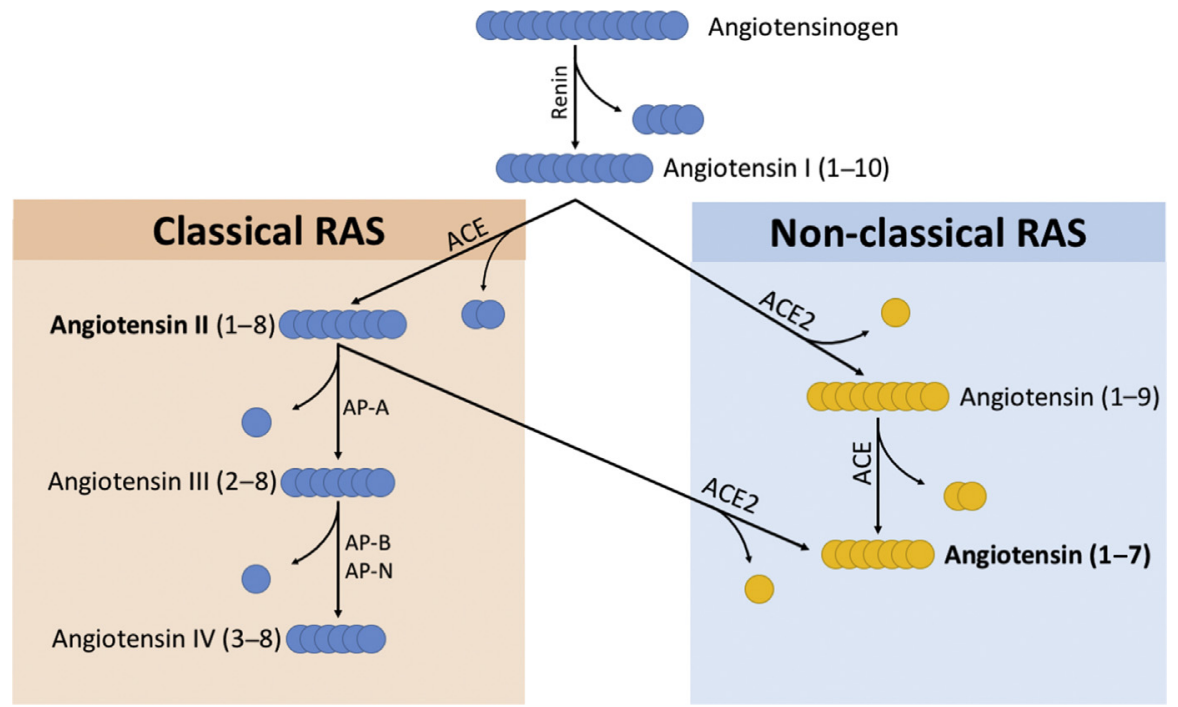

Fig. 2. RASs enzymatic cascades. AP-A, aminopeptidase A; AP-B, aminopeptidase B; AP-N, aminopeptidase $\mathrm{N}$.

\section{PHYSIOLOGY OF THE CIRCULATING CLASSIC RENIN-ANGIOTENSIN SYSTEM}

The physiologic effects of classic RAS upregulation are summarized in Fig. 3.

\section{Renal Physiology}

\section{Regulation of renal blood flow and glomerular filtration rate}

Ang II augments glomerular filtration rate (GFR) and RBF, by increasing the vasomotor tone of efferent renal arterioles, acting alongside with myogenic reflex activation and
Box 1
Mechanisms leading to renin release by the juxta-glomerular apparel

Physiologic Trigger
Renal perfusion pressure
$\mathrm{Na}+$ and $\mathrm{Cl}-$ delivery to the
macula densa
macula densa
Adrenergic activation
Angiotensin II: acute stimulus
Angiotensin II: chronic stimulus

\section{Description}
Baroreceptors in the juxta-glomerular apparel are sensitive to changes in renal perfusion pressure below $90 \mathrm{~mm} \mathrm{Hg}$.
This effect is immediately transduced to the juxta- glomerular cells, due to their intimate contact with the macula densa, forming the juxta-glomerular apparatus. Evidence suggest that this effect is mainly due to chloride depletion.
The sympathetic autonomous neural system, through a dense population of B1-noradrenergic nerves, directly stimulates renin release by the juxta-glomerular apparel. These effects are dissociated from those induced by changes in renal perfusion pressure.
Negative short-loop biofeedback by Ang II binding of $A T_{1} R$ present in the juxta-glomerular cell membrane.
This compensatory mechanism, named juxta-glomerular recruitment, increases the number of renin-secreting cells in upregulated Ang II environments.

Abbreviations: Ang II, angiotensin II; $\mathrm{AT}_{1} \mathrm{R}$, angiotensin II type 1 receptor. 


\section{Angiotensin II Angiotensin (1-7)}

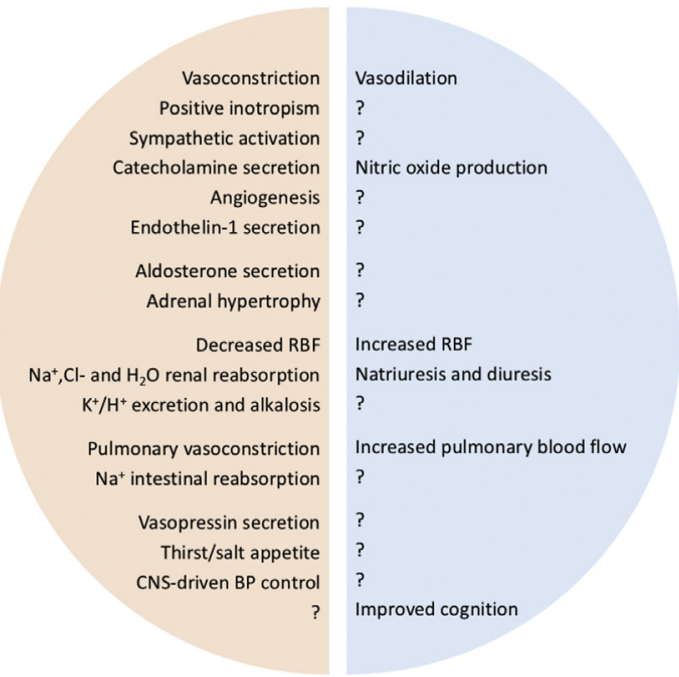

Fig. 3. Mirrorlike physiologic effects of the pivotal peptides of the classic and nonclassic RASs. BP, blood pressure; CNS, central nervous system. The question mark indicates the unknown/unexplored effect of Angiotensin (1-7), in regard to that observed with Angiotensin II upregulation.

tubulo-glomerular feedback..$^{8,9,30}$ Its effects seem maximum when blood pressure is sufficiently low to stimulate renin release. ${ }^{31}$ However, overstimulation by Ang II may decrease GFR due to excessive vasoconstriction.

\section{Sodium homeostasis and acid-base balance regulation}

Local and circulating Ang II stimulate the $A T_{1}$ R-dependent reabsorption of sodium, chloride, and bicarbonate and excretion of potassium and protons by the renal epithelia. ${ }^{9}$ It activates the apical $\mathrm{Na}^{+} / \mathrm{H}^{+}$exchanger coupled with a basal $\mathrm{Na}^{+} / \mathrm{HCO}_{3}{ }^{-}$cotransporter in the proximal tubule and the ascending limb of the loop of Henle. ${ }^{32}$ Ang II also activates $\mathrm{Na}^{+} / \mathrm{K}^{+}$ATPase anti-transporters (leading to increased kaliuresis) and pendrin, a $\mathrm{Cl}^{-} / \mathrm{HCO}_{3}{ }^{-}$anti-transporter involved in chloride reabsorption. ${ }^{33}$ Finally, aldosterone augments the recruitment of $\mathrm{Na}^{+} / \mathrm{K}^{+}$ATPase and epithelial sodium channel transporters in the distal tubules and collecting ducts. ${ }^{30}$

\section{Cardiovascular Physiology}

Although the effects of Ang II on blood pressure are partly related to extracellular volume regulation, Ang $\mathrm{II}$ is a potent vasopressor agent, via an $\mathrm{AT}_{1} \mathrm{R}$-dependent influx of calcium into smooth muscular cells cytoplasm, but is downregulated by Ang II/AT ${ }_{2} \mathrm{R}$-dependent $\mathrm{NO}$ endothelial production and bradykinin generation ${ }^{34,35}$; however, vasomotor modulation may vary between and within organs. ${ }^{36}$ Suvannapura and Levens ${ }^{37}$ observed splanchnic vasoconstriction at normal Ang II circulating levels, whereas none was observed on RBF. Finally, Ang II increases blood pressure by upregulating adrenergic stimulation and endothelin 1 (ET-1) transcription. ${ }^{38,39}$ Finally, Ang II increases cardiac output by inhibiting the vagal tone and upregulating ET-1. ${ }^{40}$

\section{Other Effects}

Ang II (and Ang III) stimulates adrenal synthesis and release of aldosterone and of catecholamines, and induces adrenal hypertrophy. ${ }^{39}$ In the brain, circulating and locally 
produced Ang II stimulates thirst and salt-seeking behavior, vasopressin release by the posterior hypophysis, and acts as a central stimulant of sympathetic nervous tone. $9,14,27,41,42$

\section{THE NONCLASSIC RENIN-ANGIOTENSIN SYSTEM} Nonclassic Renin-Angiotenin System Angiotensins

Angiotensin (1-7) is a heptapeptide produced by the proteolysis of Ang II by ACE2 (see Fig. 2). ${ }^{10}$ Cleavage of Ang (1-9) by ACE also generates Ang (1-7). Ang (1-7) is found in the plasma, heart, renal, and brain tissues, and may be excreted in the urine. Ang (1-7) binds the Mas receptor, through which most of its known effects are mediated. ${ }^{43}$ Angiotensin (1-9) is a nonapeptide generated by the ACE2-related breakdown of Ang I, acting as a competitor to ACE-related generation of Ang II. ${ }^{44}$ It is a potent cardioprotective antifibrotic agent that binds the $\mathrm{AT}_{2} \mathrm{R} .{ }^{44,45}$

\section{Angiotensin-Converting Enzyme 2}

ACE2 is the pivotal enzyme of the nonclassic RAS. ${ }^{10}$ ACE2 is transmembrane monocarboxypeptidase that converts Ang II into Ang (1-7) and Ang I into Ang (1-9). ACE2 was simultaneously discovered by 2 independent groups, using 2 complementary DNA libraries (heart and lymphoma). ${ }^{46,47}$ ACE2 is the receptor to the severe acute respiratory syndrome coronavirus, and has been identified in the kidneys, lungs, brain, heart, and testes. ${ }^{10,48,49}$ Through the generation of Ang (1-7), and the degradation of Ang II, the effect of ACE2 is tissue-protective. Due to structural differences in the binding sites of ACE and ACE2, ACE inhibitors do not inhibit the activity of ACE2. ${ }^{50}$

\section{The Mas Receptor}

The Mas receptor is a G-protein-coupled transmembrane receptor with high affinity for Ang (1-7), and little affinity for Ang II. ${ }^{43}$ The receptor is distributed along the intrarenal epithelium and vascular endothelium, in accordance with the renal and hemodynamic effects of Ang (1-7). ${ }^{51}$

\section{Nonclassic Renin-Angiotensin System and the Cardiovascular System}

Ang (1-7) induces systemic and local vasodilation, by upregulating NO production. ${ }^{51}$ Ang (1-7) and ACE2 have demonstrated cardioprotective anti-inflammatory features in an experimental model of myocardial infarction and heart failure (decreased reactive oxygen species [ROS] production and fibroblasts recruitment). ${ }^{52-57}$ However, these observations were contradicted by the observation of cardiac fibrosis after Ang (1-7) upregulation in experimental renal dysfunction, in relation to a compensatory increase in ACE. ${ }^{58}$

\section{Nonclassic Renin-Angiotenin System and Renal Function}

In the kidneys, the activation of the Mas receptor by Ang (1-7) increases RBF and GFR, natriuresis, and diuresis. ${ }^{59,60}$ Ang (1-7) and ACE2 may also present renoprotective properties, although limited by the potential compensatory upregulation of Ang II. ${ }^{60-63}$ The role of ACE2 circulating levels in the context of chronic kidney disease remains controversial. ${ }^{64,65}$

\section{RENIN-ANGIOTENSIN SYSTEMS AND THE IMMUNE SYSTEM}

Classic and nonclassic RAS modulate the innate and adaptive immune system responses, regulating inflammation, cell proliferation, fibrogenesis, and apoptosis (Box 2). ${ }^{56,57,60,66,67}$ The Ang II/ACE axis potentiates bacterial clearance, by 


\begin{tabular}{|c|c|}
\hline Angiotensin II/ACE/AT ${ }_{1} \mathrm{R}$ axis & Angiotensin (1-7)/ACE2/Mas axis \\
\hline $\begin{array}{l}\text { NFKB upregulation } \\
\text { Increase in production of ROS } \\
\text { Increase in secretion of proinflammatory cytokines } \\
\text { Collagen production } \\
\text { Macrophages/neutrophils recruitment } \\
\text { Activation of fibroblasts } \\
\text { Fibrosis, apoptosis }\end{array}$ & $\begin{array}{l}\text { NFKB downregulation } \\
\text { Downregulation of ROS production } \\
\text { Lower proinflammatory cytokine levels } \\
\text { Antiproliferative effect } \\
\text { Decrease macrophage tissue recruitment } \\
\text { Decrease fibroblast activation } \\
\text { Tissue protection }\end{array}$ \\
\hline
\end{tabular}

upregulating neutrophils and macrophages chemotaxis and activation, generation of ROS, and secretion of proinflammatory cytokines. ${ }^{28,68,69}$ Yet, lymphocytic $\mathrm{AT}_{1} \mathrm{R}$ activation inhibits $\mathrm{CD}^{+}{ }^{+}$T-cell activation. ${ }^{25,29}$ These phenomena modulate the NFKB cascade, a transcription factor involved in both the physiology and pathogenesis of septic shock and organ failure. ${ }^{70-72}$ These effects also may be directly mediated by ACE, as suggested by the effects of ACE inhibitors but not by $\mathrm{AT}_{1} \mathrm{R}$ antagonists on immunomodulation. ${ }^{73}$ In sheer contrast, activation of the Ang (1-7)/ACE2 axis inhibits ROS production, downregulates proinflammatory cytokine secretion, and has immunomodulatory tissue-protective features (see Box 2). ${ }^{60,62,66,74}$

\section{ANGIOTENSIN II IN VASODILATORY SHOCK AND SEPSIS}

In the critical setting, the upregulation of the classic RAS is a physiologic and potentially life-saving response. Ang II and renin levels are increased in the context of sepsis and significantly associated with severity of disease. ${ }^{1,6,75}$ Serum ACE concentration in patients with pulmonary sepsis were lower than in healthy volunteers, with reduced levels associated with increased mortality. ${ }^{6,76}$ In line with our understanding of Ang II effects, recent data strongly suggest that exogenous Ang II infusion decreases vasopressor dose requirements in patients with vasodilatory shock, mirroring the physiologic effects of endogenous Ang II: increase in sympathetic tone, endogenous catecholamine and vasopressin release, and direct stimulation of vascular smooth muscle cells. $^{2}$

During sepsis, Ang II upregulation may induce ROS generation and endothelial structural changes, both being pivotal physiologic responses to infection, yet also central in the pathogenesis of its most severe presentation, namely septic shock, where they become oxidative stress and endothelial dysfunction. ${ }^{1}$ Historically, although meeting promising successes in animal models, ACE inhibition did not prove to attenuate the inflammatory response in healthy volunteers exposed to endotoxemia. $^{77,78}$ Furthermore, large observational evidence was not supportive of classic RAS downregulation having protective effects against sepsis. ${ }^{79}$ Conversely, Ang II improved phagocytosis and inhibited abscess formation during experimental murine peritonitis. ${ }^{80}$ In the ATHOS-3 trial, the vast majority of patients had confirmed or suspected sepsis. Ang II infusion at the acute phase of vasodilatory shock of septic origin also may contribute to an unknown degree of inflammation enhancement and bacterial clearance. 


\section{ANGIOTENSIN-CONVERTING ENZYMES IN ACUTE RESPIRATORY DISTRESS SYNDROME}

ACE levels were respectively increased in the broncho-alveolar lavage and decreased in the serum of patients with ARDS, whereas higher circulating levels of Ang I were associated with mortality. ${ }^{5,76,81}$ The epithelial and endothelial damage observed in the course of ARDS may create an imbalance favoring classic over nonclassic RAS pathways in the lungs. ${ }^{82}$ Although little is known about Ang II in human ARDS, upregulation of the Ang II/ACE cascade in experimental ARDS worsens perfusion/ventilation mismatch, increases secretion of proinflammatory intracellular cascades and agents, and local production of ROS, all directly implicated in the disease's pathogenesis. ${ }^{4}$ Classic RAS inhibition may limit the pulmonary inflammatory response and the extent of lung injury, but has been poorly evaluated in humans. ${ }^{77,83,84}$

In contrast, growing evidence suggests the pivotal role of nonclassic RAS in lung protection in the face of acute injury. First, ACE2 was identified as being the receptor to the severe acute respiratory syndrome coronavirus, via the Spike protein. Inhibition of ACE2-coronavirus binding effectively inhibited virus replication and limited RAS-dependent acute lung injury. ${ }^{85}$ Then, experimental models of ARDS modulating Ang (1-7) and ACE2 activities have demonstrated significant lung protection (Fig. 4). ${ }^{74,86,87}$ Ang (1-7) infusion in murine experimental ARDS decreased the proinflammatory response, improved lung injury scores and lung function, and decreased cellular infiltrate in piglets with acid aspiration. ${ }^{74,82}$ These beneficial effects are mediated by downregulation of the intracellular proinflammatory $N F \kappa B$ cascade and increased NO synthesis. ${ }^{51} \mathrm{~A}$ randomized controlled trial of recombinant human ACE2 in humans with ARDS showed it decreased Ang II levels and proinflammatory mediators, and augmented plasmatic surfactant protein $D$, with no hemodynamic side effects. ${ }^{3,88}$ The effects of recombinant human ACE2 (rhACE2) may be principally mediated by its competing effects with ACE in limiting the generation of Ang II, while potentiating Ang (1-7) activity. Those findings demonstrate that ACE2-related immunomodulation in the context of ARDS may improve pulmonary outcomes, in

A

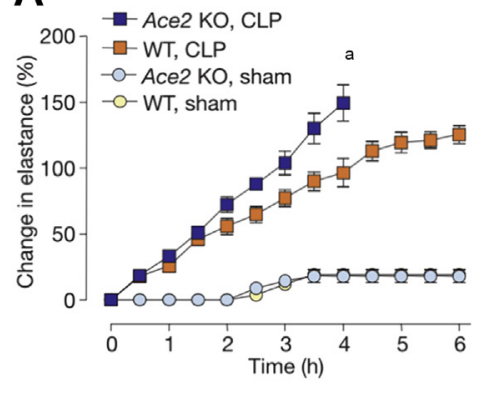

B

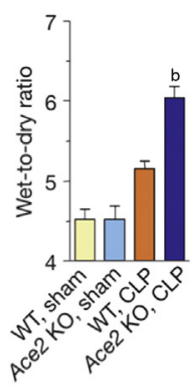

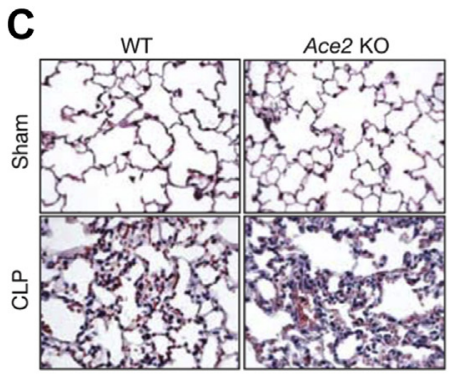

Fig. 4. ACE2 controls acute lung failure. Lung elastance $(A)$ after acute lung injury in wildtype (WT) and Ace2 knockout (KO) mice induced by cecal ligation perforation (CLP). CLPtreated Ace2 KO mice had significantly higher elastance than CLP-treated WT mice $\left({ }^{a} P<.01\right)$. Wet-to-dry weight ratios of lungs $(B)$ in CLP-treated Ace2 $\mathrm{KO}$ mice after 4 hours of ventilation was significantly increased, compared with CLP-treated WT and sham. Histopathology $(C)$ showed increased lung edema and inflammatory infiltrate in CLP-treated Ace2 knockout mice, compared to CLP-treated WT and sham. ${ }^{b} P<.05$ between CLPtreated WT and Ace2 KO mice. (From Imai Y, Kuba K, Rao S, et al. Angiotensin-converting enzyme 2 protects from severe acute lung failure. Nature 2005;436:114; with permission.) 
congruence with what we know of the downregulating effect of nonclassic RAS on the inflammatory response. Larger randomized controlled trails are necessary to confirm the promising lung protective properties of rhACE2.

\section{PLACE OF RENIN-ANGIOTENSIN SYSTEMS IN ACUTE KIDNEY INJURY}

Evidence in AKI suggests a complex picture. In patients with suspected acute tubular necrosis, angiotensinogen and Ang II expression and urinary secretion are increased, and associated with the severity of pathology and AKI risk. ${ }^{89,90}$ However, whether the upregulation of the classic RAS is the cause or the consequence of AKI remains unknown and findings may be model-dependent. Ang II upregulation improves renal function, while not aggravating medullary hypoxia, in an experimental model of septic $\mathrm{AKI}$, and attenuates intrarenal inflammation and apoptosis in murine ischemia/ reperfusion-induced AKI. ${ }^{91,92}$ Interaction of local and systemic systems may also be of importance. Renal injury may depend on renal cell $A T_{1} R$ activation, whereas a reno-protective phenotype is observed if lymphocytes $A T_{1} R$ are activated. ${ }^{93}$ The Ang II/Ang (1-7) balance may also play a role, as ACE2 knockout mice with ischemia/reperfusion-induced AKI showed worsening renal function. ${ }^{94}$ From a clinical perspective, exogenous Ang II administration in patients with vasoplegic shock and severe AKI was associated with higher survival and renal replacement therapy weaning rates. ${ }^{7}$ The role of Ang II on renal recovery after AKI, well supported by experimental data, will require further evaluation in the critical setting.

\section{INTEGRATION OF RENIN-ANGIOTENSIN SYSTEM PHYSIOLOGY IN CRITICAL ILLNESS}

Description of the physiology of the classic and nonclassic RAS has direct implications in the setting of critical illness. On the one hand, increased Ang II activity is a life-saving response to hypotension and infection, with proven effects on cardiovascular physiology and renal outcomes in the context of vasoplegic shock. ${ }^{2}$ It also implies that Ang II enhancement of hemodynamic management at the acute phase of septic shock may improve organ failure, including renal failure. Also, Ang II in the acute context may boost the proinflammatory response, with subsequent enhanced bacterial clearance, opposite to the deleterious effects of inflammation in the chronic setting. On the other hand, ACE2 enhancement decreases lung inflammation and improves lung hemodynamics and function in the setting of ARDS. ${ }^{3}$ The control of pulmonary damage by the nonclassic RAS demonstrates the central role of

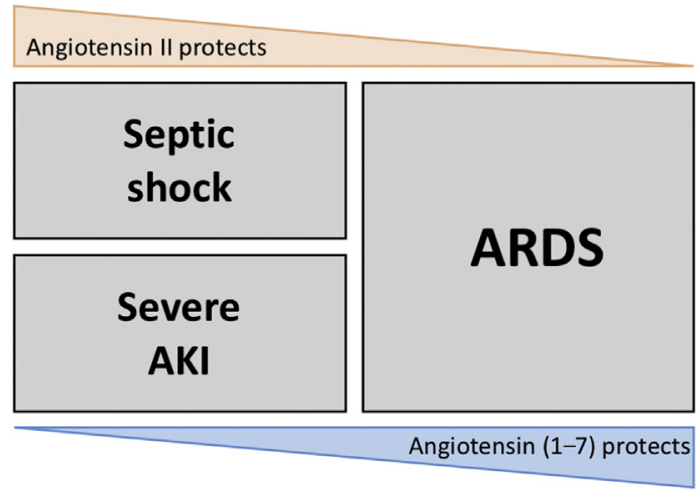

Fig. 5. The paradigm of classic and nonclassic RAS roles in critical illness. 
immunomodulation in this potentially lethal inflammation-mediated disease. Those 2 pivotal trials convey highly encouraging changes in the treatment strategies of septic shock and ARDS. Yet, their individualization at the bedside is far from being achieved, as both targeted conditions may be simultaneously present in a given individual (Fig. 5). Better understanding of how local and systemic systems interact may help target which should be favored.

\section{SUMMARY}

Our knowledge of the RASs is growing exponentially and exposing their complexity. The RAS is more than an endocrine system, and exists in most organs, with local physiologic and biological effects dissociated from the classic circulating RAS. In the context of critical illness, the regulation of the classic/nonclassic RAS balance plays a unique role in the response to vasodilatory shock and ARDS. Rapidly evolving clinical data suggest that Ang II may save lives in vasodilatory shock and accelerate renal recovery in patients with severe AKI in this setting. Conversely, ACE2 may prove an important new protective therapy in ARDS. A new chapter of the RAS, now dealing with critical illness, is being written and opens the door to a new concept in the manipulation of this ubiquitous system: inhibition in the chronic setting but activation in the acute setting.

\section{REFERENCES}

1. Doerschug KC, Delsing AS, Schmidt GA, et al. Renin-angiotensin system activation correlates with microvascular dysfunction in a prospective cohort study of clinical sepsis. Crit Care 2010;14(1):R24.

2. Khanna A, English SW, Wang XS, et al. Angiotensin II for the treatment of vasodilatory shock. N Engl J Med 2017;377(5):419-30.

3. Khan A, Benthin C, Zeno B, et al. A pilot clinical trial of recombinant human angiotensin-converting enzyme 2 in acute respiratory distress syndrome. Crit Care 2017;21(1):234.

4. Cruces P, Diaz F, Puga A, et al. Angiotensin-converting enzyme insertion/deletion polymorphism is associated with severe hypoxemia in pediatric ARDS. Intensive Care Med 2012;38(1):113-9.

5. Annoni F, Orbegozo Cortés D, Irazabal M, et al. Angiotensin converting enzymes in patients with acute respiratory distress syndrome. Intensive Care Med Exp 2015;3(1):A91.

6. Zhang W, Chen X, Huang L, et al. Severe sepsis: low expression of the reninangiotensin system is associated with poor prognosis. Exp Ther Med 2014; 7(5):1342-8.

7. Tumlin JA, Murugan R, Deane AM, et al. Outcomes in patients with vasodilatory shock and renal replacement therapy treated with intravenous angiotensin II. Crit Care Med 2018;46(6):949-57.

8. Sparks MA, Crowley SD, Gurley SB, et al. Classical renin-angiotensin system in kidney physiology. Compr Physiol 2014;4(3):1201-28.

9. Ballermann BJ, Onuigbo MA. Angiotensins. Compr Physiol 2011;(Supplement 22):104-55.

10. Chappell MC. Nonclassical renin-angiotensin system and renal function. Compr Physiol 2012;2(4):2733-52.

11. Paul M, Poyan Mehr A, Kreutz R. Physiology of local renin-angiotensin systems. Physiol Rev 2006;86(3):747-803. 
12. Yang T, Xu C. Physiology and pathophysiology of the intrarenal renin-angiotensin system: an update. J Am Soc Nephrol 2017;28(4):1040-9.

13. Matsusaka T, Niimura F, Shimizu A, et al. Liver angiotensinogen is the primary source of renal angiotensin II. J Am Soc Nephrol 2012;23(7):1181-9.

14. Wright JW, Bechtholt AJ, Chambers SL, et al. Angiotensin III and IV activation of the brain AT1 receptor subtype in cardiovascular function. Peptides 1996;17(8): 1365-71.

15. Kramar EA, Harding JW, Wright JW. Angiotensin II- and IV-induced changes in cerebral blood flow. Roles of AT1, AT2, and AT4 receptor subtypes. Regul Pept 1997;68(2):131-8.

16. Handa RK, Krebs LT, Harding JW, et al. Angiotensin IV AT4-receptor system in the rat kidney. Am J Physiol 1998;274(2 Pt 2):F290-9.

17. Bock HA, Hermle M, Brunner FP, et al. Pressure dependent modulation of renin release in isolated perfused glomeruli. Kidney Int 1992;41(2):275-80.

18. Thurau K, Schnermann J, Nagel W, et al. Composition of tubular fluid in the macula densa segment as a factor regulating the function of the juxtaglomerular apparatus. Circ Res 1967;21(1 Suppl 2):79-90.

19. Kirchheim HR, Ehmke H, Hackenthal E, et al. Autoregulation of renal blood flow, glomerular filtration rate and renin release in conscious dogs. Pflugers Arch 1987; 410(4-5):441-9.

20. Rohrwasser A, Morgan T, Dillon HF, et al. Elements of a paracrine tubular reninangiotensin system along the entire nephron. Hypertension 1999;34(6):1265-74.

21. Mackins CJ, Kano S, Seyedi N, et al. Cardiac mast cell-derived renin promotes local angiotensin formation, norepinephrine release, and arrhythmias in ischemia/reperfusion. J Clin Invest 2006;116(4):1063-70.

22. Hornig B, Kohler C, Drexler $\mathrm{H}$. Role of bradykinin in mediating vascular effects of angiotensin-converting enzyme inhibitors in humans. Circulation 1997;95(5): 1115-8.

23. Alhenc-Gelas F, Corvol P. Molecular and physiological aspects of angiotensin I converting enzyme. Compr Physiol 2011;(Supplement 22):81-103.

24. Bruneval P, Hinglais N, Alhenc-Gelas F, et al. Angiotensin I converting enzyme in human intestine and kidney. Ultrastructural immunohistochemical localization. Histochemistry 1986;85(1):73-80.

25. Coppo M, Bandinelli M, Chiostri M, et al. Persistent and selective upregulation of renin-angiotensin system in circulating T lymphocytes in unstable angina. J Renin Angiotensin Aldosterone Syst 2017;18(1). 1470320317698849.

26. Guthrie GP Jr. Angiotensin receptors: physiology and pharmacology. Clin Cardiol 1995;18(6 Suppl 3):III 29-34.

27. Allen AM, Zhuo J, Mendelsohn FA. Localization and function of angiotensin AT1 receptors. Am J Hypertens 2000;13(1 Pt 2):31S-8S.

28. Hernandez-Presa M, Bustos C, Ortego M, et al. Angiotensin-converting enzyme inhibition prevents arterial nuclear factor-kappa B activation, monocyte chemoattractant protein-1 expression, and macrophage infiltration in a rabbit model of early accelerated atherosclerosis. Circulation 1997;95(6):1532-41.

29. Zhang JD, Patel MB, Song YS, et al. A novel role for type 1 angiotensin receptors on T lymphocytes to limit target organ damage in hypertension. Circ Res 2012; 110(12):1604-17.

30. Taal MWB, Barry M. 1937-; Rector. In: Floyd C, editor. Brenner \& Rector's the kidney. 9th edition. Philadelphia: Elsevier/Saunders; 2012.

31. Hall JE, Guyton AC, Cowley AW Jr. Dissociation of renal blood flow and filtration rate autoregulation by renin depletion. Am J Physiol 1977;232(3):F215-21. 
32. Geibel J, Giebisch G, Boron WF. Angiotensin II stimulates both $\mathrm{Na}(+)-\mathrm{H}+$ exchange and $\mathrm{Na}+/ \mathrm{HCO} 3-$ cotransport in the rabbit proximal tubule. Proc Natl Acad Sci U S A 1990;87(20):7917-20.

33. Wall SM, Lazo-Fernandez Y. The role of pendrin in renal physiology. Annu Rev Physiol 2015;77:363-78.

34. Hall JE, Guyton AC, Smith MJ Jr, et al. Blood pressure and renal function during chronic changes in sodium intake: role of angiotensin. Am J Physiol 1980;239(3): F271-80.

35. Heinemann A, Wachter CH, Holzer P, et al. Nitric oxide-dependent and -independent vascular hyporeactivity in mesenteric arteries of portal hypertensive rats. $\mathrm{Br}$ J Pharmacol 1997;121(5):1031-7.

36. Myers BD, Deen WM, Brenner BM. Effects of norepinephrine and angiotensin II on the determinants of glomerular ultrafiltration and proximal tubule fluid reabsorption in the rat. Circ Res 1975;37(1):101-10.

37. Suvannapura A, Levens NR. Local control of mesenteric blood flow by the reninangiotensin system. Am J Physiol 1988;255(3 Pt 1):G267-74.

38. Rossi GP, Sacchetto A, Cesari M, et al. Interactions between endothelin-1 and the renin-angiotensin-aldosterone system. Cardiovasc Res 1999;43(2):300-7.

39. Peach MJ. Adrenal medullary stimulation induced by angiotensin I, angiotensin II, and analogues. Circ Res 1971;28(5 Suppl 2):107-17.

40. Cingolani HE, Villa-Abrille MC, Cornelli M, et al. The positive inotropic effect of angiotensin II: role of endothelin-1 and reactive oxygen species. Hypertension 2006;47(4):727-34.

41. Coble JP, Grobe JL, Johnson AK, et al. Mechanisms of brain renin angiotensin system-induced drinking and blood pressure: importance of the subfornical organ. Am J Physiol Regul Integr Comp Physiol 2015;308(4):R238-49.

42. Dendorfer A, Thornagel A, Raasch W, et al. Angiotensin II induces catecholamine release by direct ganglionic excitation. Hypertension 2002;40(3):348-54.

43. Santos RA, Simoes e Silva AC, Maric C, et al. Angiotensin-(1-7) is an endogenous ligand for the G protein-coupled receptor Mas. Proc Natl Acad Sci U S A 2003; 100(14):8258-63.

44. Flores-Munoz M, Smith NJ, Haggerty C, et al. Angiotensin1-9 antagonises prohypertrophic signalling in cardiomyocytes via the angiotensin type 2 receptor. J Physiol 2011;589(Pt 4):939-51.

45. Fattah C, Nather K, McCarroll CS, et al. Gene therapy with angiotensin-(1-9) preserves left ventricular systolic function after myocardial infarction. J Am Coll Cardiol 2016;68(24):2652-66.

46. Donoghue M, Hsieh F, Baronas E, et al. A novel angiotensin-converting enzymerelated carboxypeptidase (ACE2) converts angiotensin I to angiotensin 1-9. Circ Res 2000;87(5):E1-9.

47. Tipnis SR, Hooper NM, Hyde R, et al. A human homolog of angiotensinconverting enzyme. Cloning and functional expression as a captoprilinsensitive carboxypeptidase. J Biol Chem 2000;275(43):33238-43.

48. Chappell MC. Emerging evidence for a functional angiotensin-converting enzyme 2-angiotensin-(1-7)-MAS receptor axis: more than regulation of blood pressure? Hypertension 2007;50(4):596-9.

49. Wiener RS, Cao YX, Hinds A, et al. Angiotensin converting enzyme 2 is primarily epithelial and is developmentally regulated in the mouse lung. J Cell Biochem 2007;101(5):1278-91. 
50. Towler P, Staker B, Prasad SG, et al. ACE2 X-ray structures reveal a large hingebending motion important for inhibitor binding and catalysis. J Biol Chem 2004; 279(17):17996-8007.

51. Gwathmey TM, Westwood BM, Pirro NT, et al. Nuclear angiotensin-(1-7) receptor is functionally coupled to the formation of nitric oxide. Am J Physiol Renal Physiol 2010;299(5):F983-90.

52. Qi Y, Shenoy V, Wong F, et al. Lentivirus-mediated overexpression of angiotensin(1-7) attenuated ischaemia-induced cardiac pathophysiology. Exp Physiol 2011; 96(9):863-74.

53. Grobe JL, Der Sarkissian S, Stewart JM, et al. ACE2 overexpression inhibits hypoxia-induced collagen production by cardiac fibroblasts. Clin Sci (Lond) 2007;113(8):357-64.

54. Burrell LM, Risvanis J, Kubota E, et al. Myocardial infarction increases ACE2 expression in rat and humans. Eur Heart J 2005;26(4):369-75 [discussion: 322-64].

55. Trask AJ, Groban L, Westwood BM, et al. Inhibition of angiotensin-converting enzyme 2 exacerbates cardiac hypertrophy and fibrosis in Ren-2 hypertensive rats. Am J Hypertens 2010;23(6):687-93.

56. Tallant EA, Ferrario CM, Gallagher PE. Angiotensin-(1-7) inhibits growth of cardiac myocytes through activation of the mas receptor. Am J Physiol Heart Circ Physiol 2005;289(4):H1560-6.

57. Patel VB, Bodiga S, Fan D, et al. Cardioprotective effects mediated by angiotensin II type 1 receptor blockade and enhancing angiotensin 1-7 in experimental heart failure in angiotensin-converting enzyme 2-null mice. Hypertension 2012; 59(6): 1195-203.

58. Velkoska E, Dean RG, Griggs K, et al. Angiotensin-(1-7) infusion is associated with increased blood pressure and adverse cardiac remodelling in rats with subtotal nephrectomy. Clin Sci (Lond) 2011;120(8):335-45.

59. Heller J, Kramer HJ, Maly J, et al. Effect of intrarenal infusion of angiotensin-(1-7) in the dog. Kidney Blood Press Res 2000;23(2):89-94.

60. Pinheiro SV, Ferreira AJ, Kitten GT, et al. Genetic deletion of the angiotensin-(1-7) receptor Mas leads to glomerular hyperfiltration and microalbuminuria. Kidney Int 2009;75(11):1184-93.

61. Zhang J, Noble NA, Border WA, et al. Infusion of angiotensin-(1-7) reduces glomerulosclerosis through counteracting angiotensin II in experimental glomerulonephritis. Am J Physiol Renal Physiol 2010;298(3):F579-88.

62. Jin HY, Chen LJ, Zhang ZZ, et al. Deletion of angiotensin-converting enzyme 2 exacerbates renal inflammation and injury in apolipoprotein E-deficient mice through modulation of the nephrin and TNF-alpha-TNFRSF1A signaling. J Transl Med 2015;13:255.

63. Oudit GY, Liu GC, Zhong J, et al. Human recombinant ACE2 reduces the progression of diabetic nephropathy. Diabetes 2010;59(2):529-38.

64. Lely AT, Hamming I, van Goor H, et al. Renal ACE2 expression in human kidney disease. J Pathol 2004;204(5):587-93.

65. Reich HN, Oudit GY, Penninger JM, et al. Decreased glomerular and tubular expression of ACE2 in patients with type 2 diabetes and kidney disease. Kidney Int 2008;74(12):1610-6.

66. Bernstein KE, Khan Z, Giani JF, et al. Angiotensin-converting enzyme in innate and adaptive immunity. Nat Rev Nephrol 2018;14(5):325-36.

67. Sachse A, Wolf G. Angiotensin Il-induced reactive oxygen species and the kidney. J Am Soc Nephrol 2007;18(9):2439-46. 
68. Khan Z, Shen XZ, Bernstein EA, et al. Angiotensin-converting enzyme enhances the oxidative response and bactericidal activity of neutrophils. Blood 2017; 130(3):328-39.

69. Okwan-Duodu D, Datta V, Shen XZ, et al. Angiotensin-converting enzyme overexpression in mouse myelomonocytic cells augments resistance to Listeria and methicillin-resistant Staphylococcus aureus. J Biol Chem 2010;285(50): 39051-60.

70. Meng Y, Chen C, Liu Y, et al. Angiotensin II regulates dendritic cells through activation of NF-kappaB/p65, ERK1/2 and STAT1 pathways. Cell Physiol Biochem 2017;42(4):1550-8.

71. Abraham E. Nuclear factor-kappaB and its role in sepsis-associated organ failure. J Infect Dis 2003;187(Suppl 2):S364-9.

72. Ozawa Y, Kobori H. Crucial role of Rho-nuclear factor-kappaB axis in angiotensin Il-induced renal injury. Am J Physiol Renal Physiol 2007;293(1):F100-9.

73. Shen $X Z$, Li P, Weiss D, et al. Mice with enhanced macrophage angiotensinconverting enzyme are resistant to melanoma. Am J Pathol 2007;170(6):2122-34.

74. Zambelli V, Bellani G, Borsa R, et al. Angiotensin-(1-7) improves oxygenation, while reducing cellular infiltrate and fibrosis in experimental acute respiratory distress syndrome. Intensive Care Med Exp 2015;3(1):44.

75. Hilgenfeldt $U$, Kienapfel G, Kellermann W, et al. Renin-angiotensin system in sepsis. Clin Exp Hypertens A 1987;9(8-9):1493-504.

76. Casey L, Krieger B, Kohler J, et al. Decreased serum angiotensin converting enzyme in adult respiratory distress syndrome associated with sepsis: a preliminary report. Crit Care Med 1981;9(9):651-4.

77. Shen L, Mo H, Cai L, et al. Losartan prevents sepsis-induced acute lung injury and decreases activation of nuclear factor kappaB and mitogen-activated protein kinases. Shock 2009;31(5):500-6.

78. Graninger M, Marsik C, Dukic T, et al. Enalapril does not alter adhesion molecule levels in human endotoxemia. Shock 2003;19(5):448-51.

79. Dial S, Nessim SJ, Kezouh A, et al. Antihypertensive agents acting on the reninangiotensin system and the risk of sepsis. Br J Clin Pharmacol 2014;78(5): $1151-8$.

80. Rodgers K, Xiong S, Espinoza T, et al. Angiotensin II increases host resistance to peritonitis. Clin Diagn Lab Immunol 2000;7(4):635-40.

81. Reddy LM, Baydur L, Liebler JM, et al. The role of renin-angiotensin peptides in the pathogenesis of acute respiratory distress syndrome. Am J Respir Crit Care Med 2017;195:A4773.

82. Wosten-van Asperen RM, Lutter R, Specht PA, et al. Acute respiratory distress syndrome leads to reduced ratio of ACE/ACE2 activities and is prevented by angiotensin-(1-7) or an angiotensin II receptor antagonist. J Pathol 2011;225(4): 618-27.

83. Raiden S, Nahmod K, Nahmod V, et al. Nonpeptide antagonists of AT1 receptor for angiotensin II delay the onset of acute respiratory distress syndrome. J Pharmacol Exp Ther 2002;303(1):45-51.

84. Wosten-van Asperen RM, Lutter R, Specht PA, et al. Ventilator-induced inflammatory response in lipopolysaccharide-exposed rat lung is mediated by angiotensin-converting enzyme. Am J Pathol 2010;176(5):2219-27.

85. Kuba K, Imai Y, Rao S, et al. A crucial role of angiotensin converting enzyme 2 (ACE2) in SARS coronavirus-induced lung injury. Nat Med 2005;11(8):875-9.

86. Imai Y, Kuba K, Rao S, et al. Angiotensin-converting enzyme 2 protects from severe acute lung failure. Nature 2005;436(7047):112-6. 
87. Treml B, Neu N, Kleinsasser A, et al. Recombinant angiotensin-converting enzyme 2 improves pulmonary blood flow and oxygenation in lipopolysaccharide-induced lung injury in piglets. Crit Care Med 2010;38(2):596-601.

88. Haschke M, Schuster M, Poglitsch M, et al. Pharmacokinetics and pharmacodynamics of recombinant human angiotensin-converting enzyme 2 in healthy human subjects. Clin Pharmacokinet 2013;52(9):783-92.

89. Cao W, Jin L, Zhou Z, et al. Overexpression of intrarenal renin-angiotensin system in human acute tubular necrosis. Kidney Blood Press Res 2016;41(6):746-56.

90. Alge JL, Karakala N, Neely BA, et al. Urinary angiotensinogen and risk of severe AKI. Clin J Am Soc Nephrol 2013;8(2):184-93.

91. Lankadeva YR, Kosaka J, Evans RG, et al. Urinary oxygenation as a surrogate measure of medullary oxygenation during angiotensin II therapy in septic acute kidney injury. Crit Care Med 2018;46(1):e41-8.

92. Efrati S, Berman S, Hamad RA, et al. Effect of captopril treatment on recuperation from ischemia/reperfusion-induced acute renal injury. Nephrol Dial Transplant 2012;27(1):136-45.

93. Zhang J, Rudemiller NP, Patel MB, et al. Competing actions of type 1 angiotensin II receptors expressed on T lymphocytes and kidney epithelium during cisplatininduced AKI. J Am Soc Nephrol 2016;27(8):2257-64.

94. Fang F, Liu GC, Zhou X, et al. Loss of ACE2 exacerbates murine renal ischemiareperfusion injury. PLoS One 2013;8(8):e71433. 